\title{
Juristische Methodenlehre und Immobiliarsachenrecht
}

\author{
Deutsch-chinesische Tagung vom 21.-23.8.2013 \\ Hrsg. v. Hui Huang, Franz J. Säcker u. Claudia Schubert
}

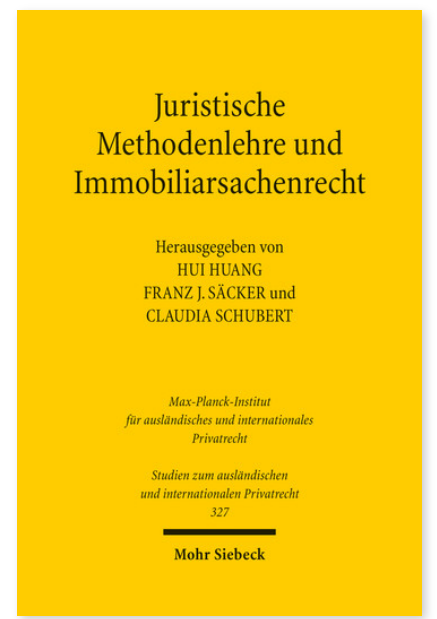

2015. X, 250 Seiten. StudIPR 327

ISBN 978-3-16-153600-7

DOI 10.1628/978-3-16-153600-7

eBook PDF 69,00€

ISBN 978-3-16-153599-4

fadengeheftete Broschur 69,00€
Die deutsche juristische Methodenlehre wurde in der Volksrepublik China rezipiert und ist auf einem abstrakten Niveau in die wissenschaftliche Diskussion eingegangen. Die fallbezogene Anwendung der Methodenlehre und ihre Leistungsfähigkeit zur Lösung juristischer Streitfragen standen im Mittelpunkt einer Tagung deutscher und chinesischer Zivilrechtswissenschaftler im August 2013 in Berlin. Die juristische Argumentation wurde anhand des Immobiliarsachenrechts, insbesondere des Wohnungseigentums, diskutiert, das in China zu einer Vielzahl von Konflikten geführt hat. Diesen deutsch-chinesischen Diskurs dokumentiert der vorliegende Tagungsband.

\section{Inhaltsübersicht}

Helmut Köhler: Die Auslegung von Gesetzen als methodisches Problem - Franz Jürgen Säcker: Der Wille des historischen Gesetzgebers bzw. der objektive Gesetzessinn am Beispiel der Entwicklung des Eigentumsbegriffs im deutschen und chinesischen Recht - Qingyu ZHU: Herrscherwille oder der Wille des Gesetzgebers? - Aufbau der Rechtsinstitutionen der unbeweglichen Sachen in China - Hartmut Oetker: Systematische und verfassungskonforme Auslegung von Gesetzen anhand des Begriffs des Immobiliareigentums aus Sicht des deutschen Sachenrechts - Shiyong TIAN: Wem gehört das Schwemmland? - Reinhard Singer: Lücken im Gesetz und deren Ausfüllung durch richterliche Rechtsfortbildung am Beispiel des zivilrechtlichen Nachbarschutzes - Hailong Jl: Lücken im Gesetz und deren Ausfüllung durch richterliche Rechtsfortbildung am Beispiel des zivilrechtlichen Nachbarschutzes in China - Jan Busche: Das Konzept des Wohnungseigentums - Weifei SUN: Einige Fragen in Bezug auf das Wohnungseigentum an Gebäuden in China - Claudia Schubert: Die Vormerkung - ein Instrument zur Sicherung des Erwerbs von Immobilien und beschränkt dinglichen Rechten an Grundstücken - Shuanggen ZHANG: Probleme bei der Vormerkung im chinesischen Recht - Jan von Hein/Lydia Beil: Gutgläubiger Erwerb von Immobilien im deutschen Recht - Baoyu LIU: Studie zur Rechtsnatur und Art der Schadensersatzhaftung des Registerorgans für Eintragungsfehler - Dirk Looschelders: Die Grundbuchberichtigung bei fehlerhaftem Grundbuch - Xiangxiang WU: Grundbuchberichtigung bei fehlerhaftem Grundbuch in China - ein Versuch der Auslegung - Torsten Körber: Hypothek und Grundschuld als Sicherungsrechte - Hongliang WANG: Die Einschränkung der Verfügungsmöglichkeit über mit einem Pfandrecht belastete Immobilien - Maik Wolf: Die Vermögenshaftung nach dem Haftungsverband der Hypothek und Grundschuld - Hui HUANG: Vom Rechsideal zur Rechtspraxis -zur Diskussion über Voraussetzungen und Schwierigkeiten bei der Entwicklung eines chinesischen Gesetzeskommentars zum Zivilrecht und die Möglichkeiten einer deutsch-chinesischen Kooperation

Hui Huang ist Professorin für Öffentliches Recht und Verfassungsrecht an der Beihang Universität, Peking.

Franz Jürgen Säcker ist Geschäftsführender Direktor des Instituts für Energie- und Regulierungsrecht Berlin an der Technischen Universität Berlin.

Claudia Schubert ist Professorin für Bürgerliches Recht, Arbeitsrecht, Handels- und Gesellschaftsrecht, Rechtsvergleichung an der Juristischen Fakultät der Ruhr-Universität Bochum.

Jetzt bestellen:

https://mohrsiebeck.com/buch/juristische-methodenlehre-und-immobiliarsachenrecht-9783161536007?no_cache=1 order@mohrsiebeck.com

Telefon: $+49(0) 7071-923-17$

Telefax: $+49(0) 7071-51104$ 